\title{
Ueber die Alloxansäure;
}

von G. Stacdeler.

Zur Gewinnung von Alloxantin aus den Mutterlangen, welche man bei der Darstellung von Alloxan mittelst Salpetersäure erhält, empfiehlt Schlieper*), die freie Säure vor Anwendung von Schwefelwasserstoff durch Kreide abzustumpfen, um einer oxydirenden Einwirkung vorzubeugen. Bei hinreichender Vorsicht ist diefs Verfahren gewifs ganz zweckmälsig; wird dagegen die Salpetersäure vollständig mit Kreide gesättigt, so entsteht gleichzeitig zweifach-kohlensaurer Kalk, der das Alloxan rassch in Alloxansäure verwandelt.

Man kann dieses Verhalten des zweifach-kohlensauren Kalkes mit Vortheil zur Darslellung der Alloxansäure anwenden. Sälligt man die verdünte saure Multerlauge mit überschüssiger Kreide, so scheidel sich alsbald zweifach-alloxansaurer Kalk theils auf der Oberfäche der Flussigkeit, theils als Niederschlag in wohl ausgebildeten Krystallen oder krystallinischen Krusten ab, von denen die beigemengte Kreide leicht durch Schlämmen getrennt werden kann. Es ist zweckmärsig, einen bedeutenden Ueberschufs von Kreide anzuwenden und häufig umzurühren, die Bildung und Abscheidung des Salzes ist dann bald beendigt. Zur Reinigung werden die beim Schlämmen zurückbleibenden schweren Krystalle in Wasser bei nicht völliger Siedehitze gelöst und die heifse Lösung filtrirt; während des Erkaltens scheidet sich der alloxansaure Kalk in weifserı Krusten ab.

Ausgezeichnet schöne Krystalle findet man häufig in dem Schaum, der sich beim Sättigen der Alloxan-Mutterlauge mit Kreide bildet. Es sind glasglänzende, vollkommen durchsich-

*) Dieso Ann. LV, 259. 
tige, schiefe sechsseitige Säulen, bei denen indefs gewöhnlich zwei Flächen so wenig hervortreten, dals die Krystalle spitzen Rhomboëdern ähnlich sehen. An trockener Luft verlieren sie alsbald einen Theil ihres Krystallwassers, werden milchweils und entziehen sich dadurch der Messung.

Der zweifach alloxansaure Kalk besteht nach Schlie p er*) aus : $\underset{\mathrm{HO}}{\mathrm{CaO}}\} \mathrm{C}_{8} \mathrm{H}_{2} \mathrm{~N}_{2} \mathrm{O}_{8}+5$ aq., er soll sowohl bei gewöhnlicher Temperatur über Schwefelsäure, als auch bei $100^{\circ}$ alles Krystallwasser verlieren, und es schien daher durch eine Bestimmung des Krystallwassergehaltes die Identität der von mir erhaltenen Krystalle mit dem auf gewöhnliche Weise bereiteten alloxansauren Salz am einfachsten nachweisbar zu sein. Meine Wasserbestimmungen wichen aber wesentlich von Schlieper's Bestimmungen ab und ich sah mich defshalb genöthigt, eine vollstündige Analyse des Salzes zu machen.

Lufttrockene, vollkommen durchsichtige Krystalle verloren über Schwefelsäure im Mittel von drei Bestimmungen 4,25 pC. Wasser, und wurden dadurch milchweifs und undurchsichtig.

Das milchweifse Salz verlor ferner bei $100^{\circ}$ im Mittel von zwei Bestimmungen 19,7 pC. Wasser.

$0,5815 \mathrm{Grm}$. des milchweilsen Salzes gaben 0,4505 Grm. Kohlensäure und 0,19 Grm. Wasser.

0,6985 Grm. desselben Salzes gaben 1,415 Grm. Ammonium - Platinchlorid.

0,3205 Grm. gaben 0,098 schwefelsauren Kalk.

Diesen Bestimmungen zufolge besteht das milchweilse, über Schwefelsäure getrocknete Salz aus : 
1 Aeq. Kalk

8 Kohlenstoff

8 "Wasserstoff

2 , Stickstoff

$14 \rightarrow$ Sauerstoff berechnet :

28 $12,50 \quad 12,59$

$48 \quad 21,43 \quad 21,12$

$8 \quad 3,57 \quad 3,63$

$28 \quad 12,50 \quad 12,72$

\begin{tabular}{rrr}
112 & 50,00 & 49,94 \\
\hline 224 & 100,00 & 100,00
\end{tabular}

Es berechnet sich aus dieser Zusammensetzung dieselbe Formel, welche Schlieper für das lufttrockene Salz aufgestellt hat. 5 Aeq. Krystallwasser betragen 20 pC., gefunden wurden $19,7 \mathrm{pC}$.

Das farblose trockene Salz enthält 1 Aeq. Wasser mehr :

$$
\mathrm{CaO}\} \mathrm{C}_{8} \mathrm{H}_{2} \mathrm{~N}_{2} \mathrm{O}_{8}+6 \text { aq., }
$$

es verliert dasselbe schon über Schwefelsäure vollständig. Der Rechnung zufolge müfste der Verlust $3,86 \mathrm{pC}$. betragen, gefunden wurden 4,25 pC. - Schiefst der zweifach-alloxansaure Kalk aus der warm gesättigten wässerigen Lösung an, so ist das Salz nicht völlig durchsichtig, der Krystallwassergehalt beträgt dann zwischen 5 und 6 Aeq.; solche Krystalle verlieren über Schwefelsäure 2 bis $3 \mathrm{pC}$. Wasser.

Aus dem Kalksalz lälst sich mit Leichtigkeit die freie Alloxansäure gewinnen. Man fällt die mit Ammoniak übersätligte concentrirte Lösung mit kohlensaurem Ammoniak, erwärmt, und scheidet den kohlensauren Kalk durch Filtration. (In der Kälte gelingt die Abscheidung des kohlensauren Kalkes nicht vollständig.) Die filtrirte Lösung des Ammoniaksalzes wird zurVerdunstung von freiem Ammoniak einige Zeit über Schwefelsäure gestellt, dann mit essigsaurem Bleioxyd gefällt und der Niederschlag gewaschen. Das Bleisalz ist frei von Ammoniak; es wird noch feucht in Weingeist suspendirt, mit Schwefelwasserstoff zersetzt und die weingeistige Alloxansäurelösung in gelinder Wärme verdunstet. 
Die Alloxansäure bleibt als farblose zähe Masse von stark saurem Geschmack zurück, die allmälig krystallinisch erstarrt. Schlieper ist der Ansicht, dafs der amorphe Zustand der Säure durch zu hohe Temperatur während des Abdampfens der Lösung herbeigeführt werde; ich erhielt sie indefs auch dann zuerst amorph, wenn ich die weingeistige Lösung bei gewöhnlicher Temperalur über Schw efelsäure verdunsten liefs.

\section{Bestimmung des Stickstoffs in salpetersauren Salzen; nach Ville.*}

Zur Bestimmung des Stickstoffs in salpetersauren Salzen verwandelt Ville die Salpetersäure in Stickoxyd, und letzteres in Ammoniak, dessen Menge ermittelt wird. Die Umwandlung der Salpetersäure in Stickoxyd wird durch Kochen der Lösung des salpetersauren Salzes mit Eisenchlorür und freier Salzsäure bewirkt.

$$
\mathrm{NO}_{5}+6 \mathrm{FeCl}+3 \mathrm{ClH}=\mathrm{NO}_{2}+3 \mathrm{Fe}_{2} \mathrm{Cl}_{3}+3 \mathrm{HO} .
$$

Die Umwandlung des Stickoxyds zu Ammoniak kann bewirkt werden, indem man ersteres mit überschüssigem Wasserstoff gemischt über Platinschwamm leitet, der fast bis zum Glühen erhitzt ist $\left(\mathrm{NO}_{2}+5 \mathrm{H}=\mathrm{NH}_{3}+2 \mathrm{HO}\right)$, welches Verfahren vollständige Umwandlung zu Ammoniak indessen nur dann giebt, wenn sehr wenig Stickoxydgas vorhanden ist, d. h. nur eine sehr kleine Menge salpetersaures Salz angewendet wurde. Für gröfsere Mengen erhält man genaue Resultate, wenn man das Stickoxyd mil überschüssigem Schwefelwasserstoff gemischt über fast rothglühenden NatronKalk leitet.

*) Compt. rend. XLI, 939 u. 987. 